\title{
(C) OPEN ACCESS \\ The effects of feedback and incentive-based insurance on driving behaviours: study approach and protocols
}

\author{
Mark Stevenson, ${ }^{1,2,3}$ Anthony Harris, ${ }^{4}$ Duncan Mortimer, ${ }^{4}$ Jasper S Wijnands, ${ }^{1}$ \\ Alan Tapp, ${ }^{5}$ Frank Peppard, ${ }^{6}$ Samantha Buckis ${ }^{7}$
}

\begin{abstract}
${ }^{1}$ Transport, Health and Urban Design, Melbourne School of Design, University of Melbourne, Melbourne, Australia ${ }^{2}$ Melbourne School of Population and Global Health, University of Melbourne, Melbourne, Australia ${ }^{3}$ Melbourne School of Engineering, University of Melbourne, Melbourne, Australia ${ }^{4}$ Centre for Health Economics, Monash University, Clayton, Australia

${ }^{5}$ Bristol Social Marketing Centre, University of the West of England, Bristol, UK ${ }^{6}$ Insurance Box Pty Ltd., Melbourne, Australia ${ }^{7}$ Transport Accident Commission, Geelong, Australia
\end{abstract}

Correspondence to Professor Mark Stevenson, Melbourne School of Design The University of Melbourne, Melbourne, VIC 3010, Australia; mark.stevenson@unimelb. edu.au

Received 28 November 2016 Revised 30 November 2016 Accepted 1 December 2016 Published Online First 10 January 2017

Check for updates

To cite: Stevenson $\mathrm{M}$ Harris A, Mortimer D, et al. Inj Prev 2018:24:89-93.

\section{ABSTRACT}

Background Road injury is the leading cause of death for young people, with human error a contributing factor in many crash events. This research is the first experimental study to examine the extent to which direct feedback and incentive-based insurance modifies a driver's behaviour. The study applies in-vehicle telematics and will link the information obtained from the technology directly to personalised safety messaging and personal injury and property damage insurance premiums.

Methods The study has two stages. The first stage involves laboratory experiments using a state-of-the-art driving simulator. These experiments will test the effects of various monetary incentives on unsafe driving behaviours. The second stage builds on these experiments and involves a randomised control trial to test the effects of both direct feedback (safety messaging) and monetary incentives on driving behaviour.

Discussion Assuming a positive finding associated with the monetary incentive-based approach, the study will dramatically influence the personal injury and property damage insurance industry. In addition, the findings will also illustrate the role that in-vehicle telematics can play in providing direct feedback to young/novice drivers in relation to their driving behaviours which has the potential to transform road safety.

\section{INTRODUCTION}

It is well established that young drivers are overrepresented in crash, injury and fatality statistics with young drivers comprising 13\% of the driving population yet comprising $22 \%$ of driver deaths in Australia. ${ }^{1}$ Over-representation of young drivers in the crash statistics is also evident in other highly motorised countries including North America and Europe. $^{2-4}$ Although the road fatality rate has declined in Australia over the past 20 years, the over-representation of young drivers in fatal crashes has not changed. ${ }^{5}$ As a result, driving is a high-risk activity for young people (ages 18-25), with the risk of a crash greatest in the novice driver's first 6 12 months of licensure. ${ }^{6}$

There are a number of risk factors contributing to the over-representation of young drivers in the crash statistics including driving at a young age, ${ }^{7}$ limited driving experience, ${ }^{8}$ being male, ${ }^{9}$ drink driving, ${ }^{8}$ driving at night ${ }^{10-12}$ and carrying passengers particularly peer passengers. ${ }^{13-15}$ Many of the risk factors have been targeted in the design and implementation of specific intervention strategies such as Graduated Licensing Systems (GLS).

Despite the gains achieved in reducing road trauma in Australia over the past four decades, there are still over 1100 deaths and 50000 hospitalised injury cases from transport-related causes each year. ${ }^{16} 17$ This raises concern about the potential for future reductions in road trauma now that road safety's 'low-hanging fruit' has already been targeted. $^{18}$ To achieve further reductions in road trauma, there is a need to trial and implement new strategies. $^{19}$

\section{In-vehicle telematics}

The introduction of in-vehicle telematics technology holds considerable promise with respect to reductions in road trauma, and there are an increasing number of insurers across Europe, North America and Australia that offer an insurance policy that requires policy-holders to have an in-vehicle telematics device installed in the on-board diagnostic (OBD) port of their registered motor vehicle. For example, InsuranceBox policy-holders in Australia are required to install the telematics device in the insured motor vehicle (see figure 1). The driver then receives direct feedback in relation to attributes such as speed relative to speed zone, driving times, distance travelled, crash events and near miss events (as defined by rapid deceleration).

In-vehicle telematics enables drivers, insurers or employers (in relation to commercial vehicles) to collect safety-specific information on a driver's on-road behaviour and performance ${ }^{20}$ and to use this information as feedback to promote safer driving. Importantly, the potential uses of in-vehicle telematics are broad and vary from vehicleto-vehicle communication, vehicle-to-infrastructure communication and direct feedback to drivers regarding vehicle behaviour, driving performance and driving conditions. In addition, there is an opportunity to link the feedback a driver receives from the in-vehicle telematics technology to various incentives to achieve desired driving behaviours.

\section{Incentives}

There is considerable evidence highlighting the impact of incentives for health behaviours including smoking cessation, physical activity, vaccination and screening, ${ }^{21}$ and blood donation ${ }^{22}$ and for nonhealth behaviours such as school attendance and educational achievement. ${ }^{23}$ Similar incentives could be used by insurers in relation to safer driving practices, based on the information obtained from the 


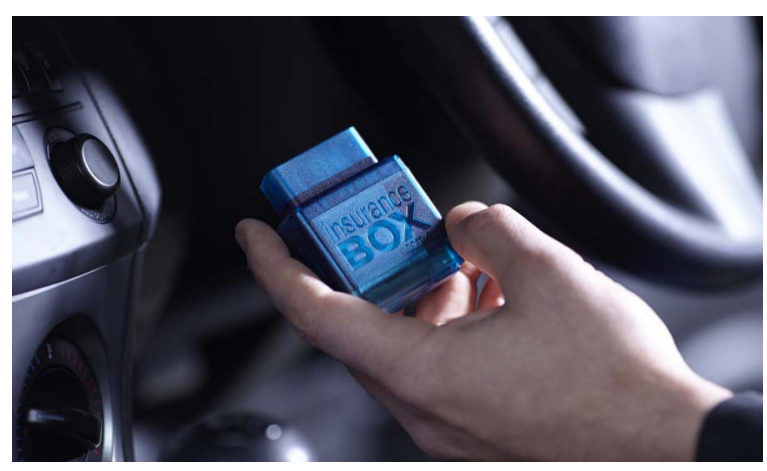

Figure 1 Telematics device.

telematics device. The permanent nature of insurance policy embedded incentives is also promising when compared with the limited effectiveness of temporary incentives. ${ }^{24}{ }^{25}$ However, the evidence regarding the effectiveness of monetary and nonmonetary incentives for safe-driving is sparse and restricted to the impact of speed cameras, drink driving legislation and the associated risks of financial penalty. ${ }^{26}$

A small number of studies have evaluated the impact of no-claim bonuses on driving behaviour, ${ }^{27}$ incentives for completion of PassPlus driving courses ${ }^{28}$ and direct financial incentives for safe driving via pay-as-you-drive (PAYD) vehicle insurance. $^{24} 29$ Early trials of PAYD insurance via in-vehicle telematics monitoring offered large monetary incentives (up to $€ 50$ / month) for keeping to the speed limit. The study observed a significant reduction in the percentage of total distance travelled at $6 \%$ or more above the local speed limit. ${ }^{24}$ Similarly, recent research found insurance-based incentives lead to fewer instances of speeding in excess of the posted speed limit. The finding by Reagan et $a l^{30}$ concurs with a similar study by Greaves and Fifer $^{31}$ that investigated variable rate charging designed to reduce speeding, night-time driving and kilometres driven which also found that insurance-based incentives were particularly effective in relation to reducing speeding. However, the large monetary rewards used in these studies are not likely to be feasible for insurance companies outside of an experiment.

Importantly, behavioural research highlights that incentives are more effective when they exploit loss aversion and gain/loss asymmetry. ${ }^{32}$ The available evidence suggests that loss aversion is a pervasive characteristic of preferences, ${ }^{33}$ with ratios of willingness to accept to willingness to pay well in excess of unity for both private goods such as mugs, chocolate or hockey tickets and public goods such as environmental amenity or public infrastructure. ${ }^{34}$ In the present context, gain/loss asymmetry would imply that loss of a discount might have a much larger impact on driving behaviour than a reward or bonus of the same dollar value. In the proposed trial, we are exploiting the asymmetry in behaviour and are testing the effectiveness of a smaller loss of a safe driving rebate as an alternative to a bonus for safe driving. If successful, this will enhance the practicality of ongoing insurance schemes.

\section{Safety messaging}

Combined with existing demographic and vehicle information, the use of in-vehicle telematics also offers a promising opportunity to enhance the safety of young drivers through providing direct feedback, tailored to their personal driving habits. Recent research found improved driving skills among high-risk young drivers who received feedback on their driving by way of in-vehicle telematics. ${ }^{35}$ Used traditionally in the organisational contexts for monitoring drivers of work-based vehicles, there is also considerable evidence indicating that in-vehicle monitoring systems are effective in reducing the instances of risky driving among young drivers. ${ }^{36} 37$

Until now, there has been no comprehensive assessment of providing individualised driver feedback along with monetary incentives on the likelihood of reducing 'at-risk' driving behaviours such as hard acceleration, severe braking and excessive speeding. This study examines the extent to which in-vehicle telematics contributes to enhancing road safety by modifying a driver's behaviour. The application of in-vehicle telematics will transform road safety as it will augment existing policies such as GLS and will become a valuable technology to assist with enforcement practices and thereby contribute to reducing the incidence and severity of road trauma across Australia and beyond.

\section{METHODS AND DESIGN Overview of study design}

To assess the elements in relation to 'at-risk' driving, we are applying a staged research approach whereby we first explore what form monetary incentives should be offered, namely what monetary level and the most effective way of delivering it. This first stage involves laboratory experiments to test the effects of various monetary incentives on unsafe driving behaviours. The findings from stage 1 contribute to the second stage namely, to assess whether the provision of direct feedback on driving performance (safety messaging) and/or monetary incentives leads to measureable change in at-risk driving of young drivers. The second stage is delivered using a randomised control trial of both direct feedback and monetary incentives as the interventions. Stage 1 will be completed over 12 months and stage 2 over 36 months.

\section{Stage 1}

In this stage, we will run a series of experiments in an advanced driving simulator to examine the effectiveness of various monetary incentive schemes at reducing at-risk driving behaviours among provisional licence (P1) holders. The simulated driving scenario will be designed in such a way that it contains a set of roadway situations likely to induce risky driving behaviours (eg, speeding, red light running and failure to give way). A total of four treatments will then be trialled using a randomised experimental design. The first two treatments will involve the use of reward-based incentives, whereby drivers can earn a certain amount of 'bonus' money for good driving performance, as measured by adherence to speed limits and traffic signals, safe gap selection and safe giving-way behaviour. The final two treatments will entail the use of punishment-based incentives, whereby drivers start with a set amount of 'bonus' money and they lose a predetermined amount for each unsafe or violation driving act they commit. The monetary amount received or lost will be varied across each of the two reward and punishment conditions to determine the most effective incentive amount to encourage safe driving behaviour. Each treatment group will contain 20 participants, comprised of young, novice drivers (aged 18-25 years) who hold a provisional (P1) driver's licence.

\section{Stage 2}

\section{Overview}

This stage involves implementing a randomised controlled trial to assess whether the provision of direct feedback on driving 
performance (safety messaging) and/or an incentive-based insurance leads to measureable change in at-risk driving. Young drivers (aged 18-25 years) who hold a provisional licence (P1) in the State of Victoria, Australia, will be recruited to participate in the study at the time they obtain their motor vehicle insurance through InsuranceBox. The participants' vehicle will be fitted with the InsuranceBox telematics device and the participants driving behaviour monitored for a 4-week 'baseline' period. Consenting participants will then be randomly assigned to one of three groups, differentiated on the basis of the intervention(s) or control group. The InsuranceBox telematics system will provide the outcome data required to evaluate the interventions and will also provide participant/driver feedback; during the intervention phase, trip-related safe and unsafe driving behaviour and practices will be provided to participants in groups 2 and 3. Participants in groups 2 and 3 will also be alerted each week by phone and encouraged to access, online, more detailed information about their individual driving behaviour and practices. Added to this, group 3 participants will receive varying monthly monetary incentives that reflect their driving behaviour for the preceding month (incorporating the findings obtained from stage 1).

We will collect data from participants over a 28 -week period, divided into two phases: (i) a 4 -week baseline period during which there is no intervention and (ii) a 24-week intervention period. Outcome data via the InsuranceBox telematics system will be collected continuously throughout the 28 -week study period. Self-report data to assess behavioural change and economic parameters including resource utilisation for the costeffectiveness evaluation will be collected from participants at several time points, including preintervention (at the end of the baseline period and prior to randomisation), and at the cessation of the intervention period.

\section{Eligibility criteria}

There are five criteria that need to be met to participate in the trial namely (i) the driver must be aged between 18 and 25 years and currently hold a P1 provisional licence in the State of Victoria, (ii) the driver will hold (or is about to take out) an InsuranceBox policy, (iii) the driver is the sole driver of the insured motor vehicle, (iv) the driver must own and use a smart phone and, finally, (v) the driver must reside in the State of Victoria throughout the duration of the trial.

\section{Randomisation}

Following the 4-week baseline phase, individual drivers will be block randomised so there are equal numbers of intervention and control participants. As this trial will not be double blind, the block size will be randomly varied to reduce the likelihood of the research assistant being aware of assignment to either the intervention or control arms.

\section{Initial assessment}

Once a driver consents to participate in the trial, a brief online, self-report questionnaire will be completed by the driver. The questionnaire will obtain demographic detail beyond what the insurer has recorded such as educational level, information on driver characteristics such as the duration and type of driver training and supervision, date of P1 licensure, duration and extent of experience in unsupervised driving, the proportion of driving for work, academic and social purposes and a 14-item assessment of risky driving behaviour. ${ }^{38}$ Key economic parameters for the cost-effectiveness evaluation will also be collected from participants at the time of recruitment and at the cessation of the intervention period.

\section{Intervention groups}

The intervention consists of both direct feedback and incentivebased insurance.

\section{Direct feedback (safety messaging)}

For each day in which driving trips have been undertaken, participants in groups 2 and 3 will be sent a summary of their driving performance via a phone app. The phone app will provide feedback on their driving performance and rank their driving performance with respect to the primary outcome of interest namely 'at-risk driving'. The participants' driving performance will be ranked using a green code (for safe low-risk driving), amber (for some at-risk driving) and red (for at-risk driving). The phone app is an integral part of the InsuranceBox policy, it has been extensively trialled and is currently being used by drivers in Victoria. At the end of each week, each participant in groups 2 and 3 will be sent a text message with a website address and a message encouraging the participant to review their driving performance on this secure website. The website provides more detailed analysis of the participants' driving performance and we will be able to monitor the participants' frequency of reviewing the website (a proxy for the fidelity of the intervention).

\section{Monetary incentive}

A monetary incentive (namely, between $\$ 0$ and $\$ 5-\$ 50$ per month based on driving performance) will be paid to the driver throughout the duration of the trial. The exact amount of the monetary incentive and how the incentive will be delivered will be decided based on the findings from stage 1 .

\section{Control group}

The control group will have the in-vehicle telematics device installed in the OBD port of the participants' motor vehicle and throughout the period of the trial, the drivers will be sent (on their smart phone) a brief weather alert that provides details on adverse weather that could affect the safety of their driving. This application is currently being used by InsuranceBox and is available to all policy-holders.

\section{Outcome measures}

The primary outcome measures, calculated over a 7-day period, will be (i) the proportion of daily trips in which the driver exceeded the posted speed limits by $10 \mathrm{~km} /$ hour, (ii) the proportion of driving trips undertaken at night and (iii) the proportion of trips in which sudden heavy braking was required (usually an evasive driving action). All three measures are captured, electronically, from the in-vehicle telematics device that will be installed in the OBD port of the participants' motor vehicle.

Further to the above outcomes, we will predict crash types by severity and quality-adjusted life year decrements due to mortality and morbidity over a 3-year period using (i) dynamic estimation of the participants' risk of crashing obtained from the in-vehicle telematics, and (ii) literature-based estimates of crash risk associated with the three primary outcome measures.

\section{Cost-effectiveness}

If either or both interventions are assessed to be effective, the cost-effectiveness of the intervention(s) will be evaluated relative to the control condition from a societal perspective. An initial trial-based economic evaluation will be conducted calculating 
the cost per outcome avoided. Costs will include annualised cost of the in-vehicle telematics technology (including monitoring and maintenance), installation, the cost of financial incentives, costs (savings) from property damage, healthcare costs (savings) secondary to fatal and non-fatal road traffic accidents and productivity losses arising from disability. The incremental costeffectiveness ratio will be estimated by dividing the estimated cost of the intervention by the observed effectiveness of the intervention with respect to the primary outcomes. We will extrapolate the outcomes from the trial to more final health outcomes over a 3-year period (particularly night-time driving and speeding) using (i) dynamic estimation of the participants' risk of crashing obtained from the in-vehicle telematics, and (ii) literature-based estimates of crash risk associated with the three primary outcome measures. For example, that exceeding the speed limit by $5 \mathrm{~km} /$ hour doubles the likelihood of a casualty crash and each additional increase in speed by $5 \mathrm{~km} / \mathrm{hour}$ further doubles the risk. ${ }^{39}$ We will calculate the additional cost per road crash avoided by severity of crash (fatal, hospitalised, non-hospitalised and property only) using standard money values for the cost of care for short-term and long-term injury ${ }^{1}$ and calculate the annual incremental cost per crash avoided, per life year gained and per disability-adjusted life year.

\section{Ethical considerations}

InsuranceBox will approach all potential participants to invite them to participate in the study. Once a young driver agrees to participate, detailed information on the study will be provided and an informed consent signed by the participant. Based on the findings from stage 1 , financial remuneration to participants in group 3 will be provided.

\section{Sample size}

A sample size of 60 participants per group is required. Based on a power of $80 \%$ and a type I error of $5 \%$, this will allow the detection of a change in the proportion of trips involving night driving or heavy braking from $5 \%$ in the comparison to $2 \%$ in the control group or the proportion of trips where the speed limit is exceeded by more than $10 \mathrm{~km} /$ hour from $10 \%$ in the comparison group to $5 \%$ in the control group.

\section{Statistical analysis}

Data will be analysed using Logistic Generalised Estimating Equation (GEE) methods. The unit over which repeated measures are correlated in the GEE will be the recruited participants (driver) with each participant trip being the repeated measure. Outcome data will be coded as a binary quantity according to whether the outcome was present during a trip. Factors which might be unbalanced after randomisation and that could confound the analysis such as the driver age and gender or socioeconomic status can be controlled through the logistic regression analysis.

\section{DISCUSSION}

Although road fatality rates have been declining over the past decade, the decline has not been observed for hospitalisations from road crashes. ${ }^{16}$ The increasing market penetration of technologies such as in-vehicle telematics provides a promising opportunity to enhance the safety of drivers and to reduce the likelihood of road trauma. This study responds to these developments and investigates the effects of driving performance feedback and insurance-based incentives on safer driving behaviour. Data recorded by the in-vehicle telematics devices of participants will provide objective outcome measurements for understanding the effects of such interventions.

Linking information obtained from the technology directly to the calculation of individual personal injury and property damage insurance premiums will alter the range of insurance and provide a permanent behavioural incentive. To date, behavioural economic approaches to changing behaviour have been short term and incrementally small in relation to changing behaviour. In contrast, there is likely to be a large effect from incentive-based insurance premiums with the potential for longlasting effects and hence, establishing a new norm for behavioural economic approaches. The findings from this research will transform the insurance industry (if the findings are successful) and will provide evidence of the effectiveness of personalised feedback to change driver behaviour and would thereby provide an accoutrement to the current GLS. In addition, it will influence the personal injury and property damage insurance industry by reducing insurance scheme liability through the adoption of telematics monitoring, encouraging behavioural change and providing direct financial incentives that reward positive behaviour in high-risk individuals.

Funding This work is supported by Australian Research Council Grant Number: LP150100680. MS is supported by a National Health and Medical Research Council Fellowship.

Competing interests None declared.

Ethics approval Melbourne University Human Research Ethics Committee, Curtin University Human Research Ethics Committee.

Provenance and peer review Not commissioned; internally peer reviewed.

Open Access This is an Open Access article distributed in accordance with the Creative Commons Attribution Non Commercial (CC BY-NC 4.0) license, which permits others to distribute, remix, adapt, build upon this work non-commercially, and license their derivative works on different terms, provided the original work is properly cited and the use is non-commercial. See: http://creativecommons.org/ licenses/by-nc/4.0/

\section{REFERENCES}

1 BITRE. Cost of road crashes in Australia 2006. Report 118. Canberra, ACT: Bureau of Infrastructure, Transport and Regional Economics, 2010.

2 Toroyan T, Peden M. Youth and Road Safety. Geneva: World Health Organization, 2007.

3 Twisk DAM, Stacey C. Trends in young driver risk and countermeasures in European countries. J Safety Res 2007;38:245-57.

4 National Research Council, Institute of Medicine, Transportation Research Board. Preventing teen motor crashes: contributions from the behavioral and social sciences. Workshop report. Washington DC: The National Academic Press, 2007.

5 ATSB. Young people and road crashes. Canberra, ACT: Australian Transport Safety Bureau, 2004

6 Young driver safety and graduated licensing. Discussion paper. Kew, VIC: VicRoads, 2005.

7 Williams AF, Karpf RS, Zador PL. Variations in minimum licensing age and fatal motor vehicle crashes. Am J Public Health 1983;73:1401-3.

8 Mayhew DR, Simpson HM. The safety value of driver education and training. Inj Prev 2002;8(Suppl 2):ii3-8.

9 Macdonald WA. Young driver research program - a review of information on young driver performance characteristics and capacities. Federal Government's Road Safety Initiative CR 129. Canberra, ACT: Federal Office of Road Safety, 1994.

10 Williams AF. Nighttime driving and fatal crash involvement of teenagers. Accid Anal Prev 1985; 17:1-5

11 Williams AF, Preusser DF, Ulmer RG, et al. Characteristics of fatal crashes of 16-year-old drivers: implications for licensure policies. J Public Health Policy 1995;16:347-60.

12 Adams C. Probationary and non-probationary drivers' nighttime crashes in Western Australia, 1996-2000. J Safety Res 2005;36:33-7

13 Preusser DF, Ferguson SA, Williams AF. The effect of teenage passengers on the fatal crash risk of teenage drivers. Accid Anal Prev 1998;30:217-22.

14 Chen LH, Baker SP, Braver ER, et al. Carrying passengers as a risk factor for crashes fatal to 16- and 17-year-old drivers. JAMA2000;283:1578-82.

15 Lam LT, Norton R, Woodward $M$, et al. Passenger carriage and car crash injury: a comparison between younger and older drivers. Accid Anal Prev 2003;35:861-7.

16 BITRE. Road trauma Australia, 2014 statistical summary. Canberra, ACT: Bureau of Infrastructure, Transport and Regional Economics, 2015. 
17 Pointer S. Trends in hospitalised injury, Australia: 1999-00 to 2010-11. Injury research and statistics series no. 86. Cat. no. INJCAT 162. Canberra, ACT: Australian Institute of Health and Welfare, 2013.

18 Özgüner Ü, Stiller C, Redmill K. Systems for safety and autonomous behavior in cars: the DARPA grand challenge experience. Proc IEEE 2007;95:397-412.

19 Stevenson M, Thompson J. On the road to prevention: road injury and health promotion. Health Promot J Austr 2014;25:4-7.

20 Horrey WJ, Lesch MF, Dainoff MJ, et al. On-board safety monitoring systems for driving: review, knowledge gaps, and framework. J Safety Res 2012;43:49-58.

21 Giles EL, Robalino S, McColl E, et al. The effectiveness of financial incentives for health behaviour change: systematic review and meta-analysis. PLOS ONE 2014;9: e90347.

22 Mortimer D, Ghijben P, Harris A, et al. Incentive-based and non-incentive-based interventions for increasing blood donation. Cochrane Database Syst Rev 2013;(1): CD010295.

23 Gneezy U, Meier S, Rey-Biel P. When and why incentives (don't) work to modify behavior. J Econ Perspect 2011;25:191-209.

24 Bolderdijk J, Steg L. Pay-as-you-drive vehicle insurance as a tool to reduce crash risk. Results so far and further potential. Discussion paper 2011-23. OECD/ITF, 2011. doi: $10.1787 / 5 \mathrm{~kg} 29 \mathrm{~s} 5 \mathrm{cp} 90 \mathrm{w}$-en

25 Gneezy U, Rustichini A. A fine is a price. J Legal Stud 2000;29:1-17.

26 Avineri E, Goodwin P. Individual behaviour change: evidence in transport and public health. London: The Department for Transport, 2010.

27 Vaaje T. Rewarding in insurance: return of part of premium after a claim-free period. In: Koornstra MJ, Christensen J, eds. Proceedings of the International Road Safety Symposium in Copenhagen, Denmark, September 19-21, 1990. Leidschendam: SWOV Institute for Road Safety Research, 1991:154-6.

28 Greer J. The Fife PassPlus initiative. 67th Road Safety Congress: Safer driving - the road to success. Stratford-upon-Avon, 2002.
29 Bolderdijk JW, Knockaert J, Steg EM, et al. Effects of pay-as-you-drive vehicle insurance on young drivers' speed choice: results of a Dutch field experiment. Accid Anal Prev 2011;43:1181-6.

30 Reagan IJ, Bliss JP, Van Houten R, et al. The effects of external motivation and real-time automated feedback on speeding behavior in a naturalistic setting. Hum Factors 2013;55:218-30.

31 Greaves S, Fifer $\mathrm{S}$. Analysis of a financial incentive to encourage safer driving practices. Proceedings of the 34th Australasian Transport Research Forum. Adelaide, 2011.

32 Kahneman D, Tversky A. Prospect theory: an analysis of decision under risk. Econometrica 1979:47:263-91.

33 Knetsch JL, Wong W-K. The endowment effect and the reference state: evidence and manipulations. J Econ Behav Organ 2009;71:407-13.

34 Bischoff I. Endowment effect theory, prediction bias and publicly provided goods: an experimental study. Environ Resour Econ 2008;39:283-96.

35 Tapp A, Pressley A, Baugh M, et al. Wheels, skills and thrills: a social marketing trial to reduce aggressive driving from young men in deprived areas. Accid Anal Prev 2013;58:148-57.

36 Farmer CM, Kirley BB, McCartt AT. Effects of in-vehicle monitoring on the driving behavior of teenagers. J Safety Res 2010;41:39-45.

37 McGehee DV, Raby M, Carney C, et al. Extending parental mentoring using an event-triggered video intervention in rural teen drivers. J Safety Res 2007;38:215-27.

38 Ivers $R$, Senserrick T, Boufous $S$, et al. Novice drivers' risky driving behavior, risk perception, and crash risk: findings from the DRIVE study. Am J Public Health 2009;99:1638-44

39 Kloeden CN, McLean AJ, Glonek G. Reanalysis of travelling speed and the risk of crash involvement in Adelaide South Australia. Road safety research report CR 207. Canberra, ACT: Australian Transport Safety Bureau, 2002. 